\title{
MISMATCH NEGATIVITY IN YOUNG CHILDREN OF ALCOHOLICS FROM HIGH-DENSITY FAMILIES
}

Authors: Socorro Rodríguez Holguín, Montserrat Corral, Fernando Cadaveira

This is the peer reviewed version of the following article: Rodríguez Holguín, S., Corral, M., Cadaveira, F. (1998). Mismatch negativity in young children of alcoholics from highdensity families. Alcoholism, Clinical and Experimental Research, 22(6), 87-96. https://doi.org/10.1111/j.1530-0277.1998.tb03620.x

This article may be used for non-commercial purposes in accordance with Wiley, Research Society on Alcoholism, and International Society for Biomedical Research on Alcoholism terms and conditions for use of self-archived versions. 


\title{
Mismatch negativity in young children of alcoholics from high- density families ${ }^{1}$
}

\author{
Socorro Rodríguez Holguín, Montserrat Corral, Fernando Cadaveira \\ Department of Clinical Psychology and Psychobiology. University of Santiago de Compostela, \\ Galicia, Spain
}

\begin{abstract}
The mismatch negativity (MMN) component of event-related potentials was recorded from a group of young children of alcoholics ( $n=19,8$ females) with a high-density family history of alcoholism and from a control group ( $n=23,12$ females), between 8 and 15 years of age. $A$ dichotic listening task was used, and subjects had to pay attention to an oddball paradigm in one ear and ignore the stimuli in the other ear. The event-related potentials elicited by the standard unattended tones were subtracted from those elicited by the infrequent deviant unattended tones, and the MMN was measured at 10 frontal and central electrodes. No group differences were observed in peak latency, peak amplitude, and mean amplitude of the MMN. These results indicated that preattentive mechanisms of mismatch detection were not impaired in young subjects at high risk for alcoholism. Results are discussed in relation to differences in electrophysiological indexes of automatic versus controlled information processing and in relation to the characteristics of the sample.
\end{abstract}

Key Words: Event-Related Potentials (ERPs), Mismatch Negativity (MMN), Alcoholism, High Risk, Children of Alcoholics.

Research into family risk for alcoholism using event-related potentials (ERPs) has provided evidence of anomalies in the neurophysiological processing of stimuli in children of alcoholics. Differences between subjects at risk for alcoholism and controls have been reported affecting the P300 (P3b) component elicited by relevant (target) stimuli during focused attention tasks. This positive-going centroparietal wave has been found to be diminished in amplitude in nonaffected children of alcoholics, both young ${ }^{1-6}$ and adult ${ }^{7-15}$. The reduced P300 reported in alcoholics has also been associated more with a family history of alcoholism than to alcohol consumption itself ${ }^{16,17}$. The diminished P300 in subjects at risk for alcoholism has been interpreted as an index of a deficiency in cortical inhibition necessary to limit cortical excitation to task specific areas. This lack of inhibition would underlie a deficit in the ability to compare the incoming stimuli with the template of the nontarget stimuli in working memory, so that each income event is evaluated anew ${ }^{18}$. Although some other studies have not found differences between high-risk (HR) subjects and controls in P300 amplitude ${ }^{19-28}$, and some have related the reduction of P300 with the confluence of family history of alcoholism and a history of other psychopathological disorders, such as antisocial personality disorder ${ }^{11}, 29-31$, reviews of the literature have considered that diminished P300 is a valuable candidate as a phenotypic marker of vulnerability to alcoholism ${ }^{32,33}$. Several factors, such as the sensory modality and difficulty of the task, the age of the

\footnotetext{
${ }^{1}$ Received for publication February 11, 1998; accepted April 14, 1998
} 
subjects, the sample selection criteria or the presence/absence of other psychiatric problems in the families, may explain the discrepancies among studies ${ }^{32,33}$.

The ERP components related to the processing of infrequent irrelevant events have also been assessed in children of alcoholics in several recent reports. Nontarget infrequent stimuli interspersed in an oddball task elicit a P300 component with a parietocentral distribution in the context of an easy perceptual discrimination task, or a P300 component larger in amplitude and shorter in latency at the central and frontal scalp locations (P3a) in the context of a difficult perceptual discrimination task ${ }^{34,}{ }^{35}$. Using an easy discrimination visual task, nontarget infrequent stimuli elicited a reduced P300 in a sample of young HR subjects (9 to 18 years old) ${ }^{36}$. A similar paradigm elicited a delayed latency of the parietocentral P300 in males and a delayed latency of the frontal $\mathrm{Ne}$ wave in females, sons, and daughters of alcoholic fathers from 8 to 15 years of age ${ }^{37}$. In the context of a difficult perceptual discrimination between target and standard, a well-differentiated infrequent non-target elicited a smaller P3a in a group of adult children of alcoholics (19 to 30 years old) than in the control group at frontal, central, parietal, and temporal electrodes. Therefore, the abnormalities associated with a vulnerability to alcoholism are not limited to the processing of the relevant information.

Another ERP component associated with the processing of infrequent irrelevant stimuli is the mismatch negativity (MMN), obtained when a physically deviant sound occurs in a series of unattended standard auditory stimuli. MMN has been interpreted as an index of the automatic detection of a mismatch between an incoming deviant stimulus and the sensory-memory trace produced by a repetitive unattended stimulus ${ }^{39}$. It represents a preattentive mechanism that can act as a switch for attention focus when deviation exceeds a threshold, and is then followed by P3a ${ }^{39}$. Evaluation of MMN in subjects at risk for alcoholism may clarify if the electrophysiological abnormalities reported in the controlled processing of infrequent relevant (P3b) and irrelevant ( $\mathrm{Ne}$, P3a) attended stimuli are already present in the automatic detection of unattended deviant events.

MMN has been found to be sensitive to the acute effects of alcohol, with low doses of ethanol causing a reduction in MMN amplitude ${ }^{40-42}$. It has been hypothesized that the substance only affects the frontal MMN subgenerators, because MMN reduction did not occur at electrodes located over the Silvian fissure 42. With regard to the effect of chronic alcoholism, one study assessed the ERPs elicited by infrequent tones in an unattended oddball paradigm during a reading task in detoxified alcoholics $(n=63)$, compared with controls ${ }^{43}$. The $\mathrm{N} 2$ elicited by these infrequent unattended stimuli was used as an index of the automatic mismatch processes, and revealed a decreased amplitude in the alcoholic group. Another report found a delayed rise in MMN in a group of 23 detoxified chronic alcoholics ${ }^{44}$.

Two reports have recently assessed MMN in subjects at genetic risk for alcoholism. One compared a sample of 20 children of alcoholics and 20 controls aged between 9 and $18{ }^{45}$. The MMN elicited by a deviant auditory tone during a reading task was measured with the aim of determining if the dysfunction in effortful information processing indicated by P300 reduction in these subjects also affects automatic processing. No differences were observed between groups in the amplitude, latency, and scalp topography of MMN, suggesting that the reported differences in MMN in alcoholics may represent a state marker for alcoholism. 
The other study assessed MMN in a group of 16 young adult alcoholics (18 to 26 years old) ${ }^{46}$. Based on the hypothesis that subjects at risk for alcoholism present a deficit in cortical inhibition indicated by P300 amplitude anomalies, MMN was measured as an index for the activity of the excitatory glutamatergic system. The MMN elicited by an oddball unattended paradigm during a reading task revealed a greater amplitude in the HR subjects than in the controls. This result supports the hypothesis of an increased neural hyperexcitability in subjects with genetic vulnerability to alcoholism. Therefore, there is no agreement about the presence of deficits in the neurophysiological indexes of automatic processing of information in the auditory modality in subjects with a genetic vulnerability to alcoholism.

To contribute to the clarification of this issue, the present study evaluated the MMN obtained during a dichotic listening task in a sample of young subjects, both males and females, between 8 and 15 years of age. A group composed of children of alcoholics with a positive family history of alcoholism and without other psychopatholgical disorders in the families was compared with a control group with a negative history of alcoholism and psychopathological disorders.

\section{METHODS}

\section{Subjects}

The subjects were 42 males and females ranging from 8 to 15 years of age. The high risk $(H R)$ group $(n=19,8$ females, mean $=11.7 \pm 2.1$ years $)$ consisted of children of alcoholic fathers with a high-density family history of alcoholism. The subjects in the HR group were selected from community treatment centers, where their fathers had been diagnosed and treated. All of the alcoholic fathers met DSM-III-R ${ }^{47}$ criteria for alcohol dependence (diagnosis made by the staff of the centers was corroborated during the selection interview). Those with a history of psychopathological problems other than secondary to alcoholism (according to the clinical history from the centers and the information collected during the selection interview) were excluded. The family history of alcoholism was ascertained from fathers and mothers using the family history interview method. Only children of alcoholic fathers who had at least two other first- or second-degree alcoholic relatives were included. The control group ( $n=23,12$ females, mean $=11.4 \pm 2.4$ years) consisted of children of nonalcoholic fathers without a family history of alcoholism. To guarantee homogeneity with regard to sociodemographic variables, control subjects were recruited from voluntary families from schools in the region within the same age range and socioeconomic status as those in the HR group. Control families who reported any problems with alcohol in firstor second-degree relatives were excluded.

Other exclusionary criteria were similar for the two groups, and included consumption of alcohol or other drugs, a history of psychopathological disorders, prenatal exposure to alcohol, developmental or school retardation, a positive neurological history, major medical problems, current medication, noncorrected sensory deficits, a family history of major mental diseases, and problems of alcoholism in the mother. Information about inclusion and exclusion criteria was obtained through detailed semistructured interviews with both the children and their fathers and mothers. The interviews were a translated and adapted version of the "Semi-Structured Assessment for the Genetics of Alcoholism", versions for adults, children, adolescents, and parents, as well as the Family History Assessment Module, designed by the Collaborative Study on the 
Genetics of Alcoholism (COGA) ${ }^{48}$. Questions about individual and familial psychopathological problems were based on DSM-III-R criteria and at least one other diagnostic classification system. Information was also obtained during the interviews about demographic data, family relations, school achievement, and social activities.

The final sample was well-matched on age, socioeconomic status, and education (all subjects were enrolled in compulsory schooling and followed the grade according to age) between the groups (Table 1). Subjects from the two groups were randomly distributed across environmental variables, such as the ERPs assessment time (time of day, month), recency of food ingestion, or handeness. 49 The presentation order of the tasks was the same for all the subjects.

\section{Procedure}

Families who met requirements for the study were asked to participate; those who agreed signed a consent form and then received an appointment for the assessment. When children arrived at the laboratory (early in the morning or in the afternoon), the members of staff showed them the laboratory and explained the contents and procedure of the assessment.

Table 1. Demographic Characteristics of Control and HR Groups

\begin{tabular}{lccc}
\hline & $\begin{array}{c}\text { Controls } \\
(\mathrm{n}=23)\end{array}$ & $\begin{array}{c}\text { HR } \\
(\mathrm{n}=19)\end{array}$ & $p$ \\
\hline Gender (f/m) & $12 / 11$ & $8 / 11$ & - \\
Age (range) & $8-15$ & $8-15$ & -- \\
$\quad$ mean (SD) & $11.4(2.4)$ & $11.7(2.1)$ & 0.674 \\
Education (years) & $5.6(2.4)$ & $6.4(2.0)$ & 0.241 \\
$\begin{array}{l}\text { Handedness } \\
\text { (R/L/A) }\end{array}$ & $20 / 3 / 0$ & $17 / 1 / 1$ & $0.285^{*}$ \\
\hline $\begin{array}{l}\text { f/m, female/male; R/L/A, right/left/ambidextrous } \\
{ }^{*} \chi^{2} \text { comparison }\end{array}$ & &
\end{tabular}

Once electrodes had been put in place, subjects sat in a comfortable armchair, in an electrically isolated, sound- and light-attenuated laboratory. They received general instructions to avoid moving during the tests and to pay attention to the individual instructions before each test. Subjects were tested using several experimental paradigms. This report includes the ERP waveforms recorded during the performance of a dichotic listening task.

The stimuli were pure sine-wave monoaural tones of $50 \mathrm{msec}(10 \mathrm{msec}$ rise/fall time) generated by the Stirn module of a Neuroscan system and presented dichotically at an intensity of $90 \mathrm{~dB}$ SPL through headphones. 1000- $\mathrm{Hz}$ standard tones (probability of 0.8 ) and $1500-\mathrm{Hz}$ deviant tones (probability of 0.2 ) were randomly presented with an interstimulus interval of $600 \pm 100 \mathrm{msec}$. Two blocks of 400 stimuli (200 to each ear) were presented in two consecutive runs, with a 3-min interblock interval. In each run, subjects were told to pay attention to stimuli in a designated ear and to ignore stimuli in the other, and to press a button with the preferred hand when a deviant tone was 
detected among the attended stimuli. In the second run, they had to pay attention to the tones in the other ear. The assignment of each ear when listening was counterbalanced across subjects. A brief training sample was run to ensure acceptable task performance. Response time, correct responses, and false alarms were recorded.

\section{ERP Recording}

Electroencephalographic (EEG) activity was recorded at 10 scalp sites: Fp1, Fp2, Fz, F3, F4, F7, F8, Cz, C3, and C4 (Standard Electrode Position Nomenclature ${ }^{50}$ ), using tin electrodes inserted in an electrocap (Electro-Cap International, Inc.), referred to linked earlobes, and with a forehead ground. Additional electrodes were used to monitor eye movements (supraorbital and the outer canthus of the left eye, referred to an infraorbital electrode). EEG activity was filtered $(0.1$ to $30 \mathrm{~Hz})$ and amplified $10 \mathrm{~K}$ (Grass Neurodata Acquisition System, mod. 12, connected to a Neuro Scan, Inc., system for the analog-to-digital conversion and storage). Impedance values were kept at $5 \mathrm{~K} \Omega$ or below.

EEG was continuously sampled at a rate of $256 \mathrm{~Hz}$. The signal was processed off-line: first, EEG was corrected for ocular artifacts, using the algorithm developed by Semlitsch and colleagues ${ }^{51}$; then, EEG was epoched from 50 msec prestimulus to 500 msec poststimulus, linear detrends were eliminated, and the signal was adjusted to 0 $\mu \mathrm{V}$ prestimulus baseline. Trials exceeding $\pm 100 \mu \mathrm{V}$ at any scalp electrode were identified by visual inspection and rejected. The first 10 epochs of each block, epochs corresponding to deviant stimuli preceded by another deviant stimulus, and those corresponding to false alarm responses were also rejected. Finally, trials were averaged according to type of stimuli and attention condition.

\section{Data Analysis}

To obtain MMN, difference waves were obtained in each subject at each electrode by subtracting the ERPs elicited by the nonattended standards from the ERPs elicited by the nonattended deviants in each ear. Because replicability of the difference waves obtained in the two ears was high in all subjects, the difference waves from the two ears were averaged, and statistical analyses were performed on these averages.

The MMN was determined as the largest amplitude negative peak within a time window from 100 to $250 \mathrm{msec}$. Peak latencies (msec), peak amplitudes $(\mu \mathrm{V})$, and mean amplitudes $(\mu \mathrm{V})$ of MMN at each electrode were measured with a semiautomatic peak detection program. First, a computer algorithm was used to search for the maximum negative peak amplitude for each electrode within the predefined latency window; peaks were then verified and adjusted by visual inspection, and those that were doubtful were revised by a second experienced member of the laboratory, blind to the risk status of the subject and the initial peak. Amplitude and latency values were automatically exported to an ASCII file for subsequent analyses.

The MMN measurements were organized into three electrode groupings: frontal pole and inferior frontal (Fp1, Fp2, F7, F8), medial frontal (F3, F4, Fz), and central (C3, C4, $\mathrm{Cz}$ ). Preliminary Risk Group by Gender and Risk Group by Age analyses were made for determining the inclusion of gender and age variables in the design. Because there were no significant interactions in these analyses, both genders were considered 
jointly, and age was included as a covariate. Therefore, a Risk Group by Electrode mixed-model analysis of covariance (ANCOVA), with the Risk Group as betweensubjects factor, the Electrode as within-subject factor, and Age as a covariate were used to assess group differences in the MMN peak latency, peak amplitude, and mean amplitude in each of the electrode groupings. Degrees of freedom were corrected by the conservative Greenhouse-Geisser estimate when appropriate. The behavioral data (response time, percentage of correct responses, and false alarms) were assessed using an ANCOVA comparison between the risk groups with age as a covariate.

\section{RESULTS}

\section{Behavioral Performance}

Table 2 summarizes the behavioral data for each group. No significant differences between the risk groups were observed for response time, percentage of correct responses, and percentage of false alarms $(p>0.05)$.

Table 2. Behavioral Data for Control and HR Groups

\begin{tabular}{|c|c|c|c|c|c|}
\hline & \multicolumn{2}{|c|}{$\begin{array}{l}\text { Controls } \\
(n=23)\end{array}$} & \multicolumn{2}{|c|}{$\begin{array}{c}\text { HR } \\
(n=19)\end{array}$} & \multirow[b]{2}{*}{$p$} \\
\hline & Mean & SD & Mean & SD & \\
\hline Response time (msec) & 510 & 76.9 & 499 & 91.5 & 0.799 \\
\hline$\%$ Correct & 70.5 & 20.7 & 69.1 & 16.3 & 0.542 \\
\hline$\%$ False alarms & 1.4 & 3.7 & 2.9 & 5.6 & 0.284 \\
\hline
\end{tabular}

\section{ERP Measurements}

Figure 1 illustrates the grand mean of the difference waves (deviant minus standard) for the control and HR groups. The difference waves were clearly negative at all the electrodes in the latency range of MMN (100 to $250 \mathrm{msec}$ ), due to the more negative ERPs elicited by deviant than standard unattended stimuli. The frontocentral distribution of the MMN usually reported in the literature was corroborated at this study, where the two groups manifested larger amplitudes in the medial frontal and medial central electrodes than in the frontal pole and inferior frontal electrodes. The descriptive statistics of the data are summarized in Table 3.

The mixed-model ANCOVAs of the MMN parameters for the unattended condition demonstrated no significant differences between the two risk groups at any region for the peak latency [pole-inferior frontal: $F(1,39)=2.95, p>0.094$; medial frontal: $F(1,39)$ $=1.02, p>0.320$; central: $F(1,39)=2.02, p>0.163$ ], peak amplitude [pole-inferior frontal: $F(1,39)=0.58, p>0.450$; medial frontal: $F(1,39)=0.08, p>0.778$; central: $F(1,39)=0.56, p>0.457$ ], and mean amplitude [pole-inferior frontal: $F(1,39)=0.02, p$ $>0.894$, medial frontal: $F(1,39)=0.55, p>0.465$; central $F(1,39)=0.97, p>0.332$ ]. There were also no significant $(p>0.05)$ Risk Group by Electrode interactions. Individual ANCOVAs at each electrode confirmed the absence of significant group differences at any location. 


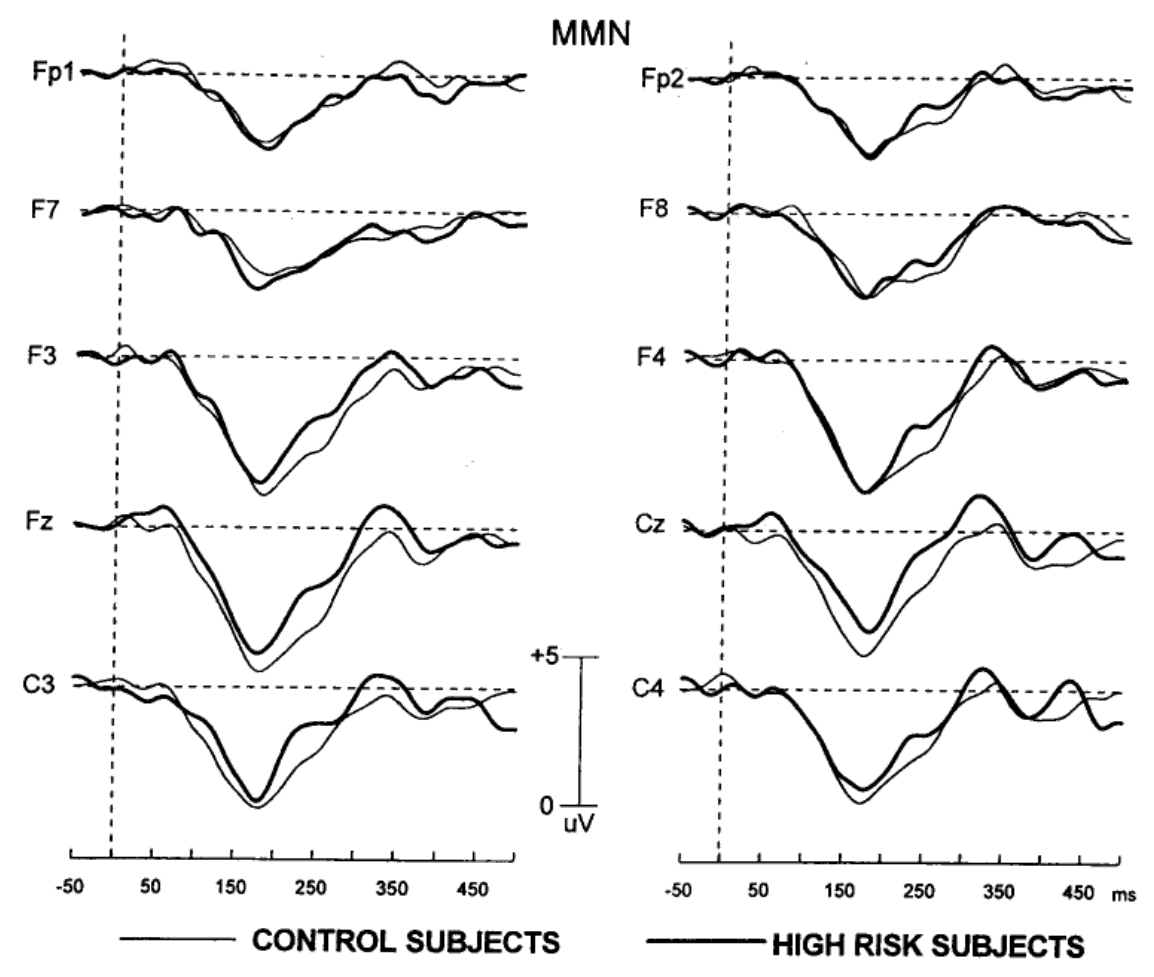

Fig. 1. Grand mean waveforms of the MMN for the control $(n=23)$ and HR $(n=19)$ groups.

Table 3. Mean MMN Peak Latency (msec), Peak Amplitude $(\mu, \mathrm{V})$, and Mean Amplitude $(\mu \mathrm{V})$ within a Latency Window of 100-250 msec in the Control and HR

\begin{tabular}{|c|c|c|c|c|c|c|c|c|c|c|c|c|}
\hline & \multicolumn{6}{|c|}{ Controls $(n=23)$} & \multicolumn{6}{|c|}{$\mathrm{HR}(\mathrm{n}=19)$} \\
\hline & \multicolumn{2}{|c|}{ Peak latency } & \multicolumn{2}{|c|}{ Peak amplitude } & \multicolumn{2}{|c|}{$\begin{array}{c}\text { Mean } \\
\text { amplitude }\end{array}$} & \multicolumn{2}{|c|}{ Peak latency } & \multicolumn{2}{|c|}{$\begin{array}{c}\text { Peak } \\
\text { amplitude }\end{array}$} & \multicolumn{2}{|c|}{$\begin{array}{c}\text { Mean } \\
\text { amplitude }\end{array}$} \\
\hline & Mean & SD & Mean & SD & Mean & SD & Mean & SD & Mean & SD & Mean & SD \\
\hline Fp1 & 168.64 & 23.64 & -2.89 & 2.85 & -1.52 & 2.64 & 183.28 & 25.40 & -2.92 & 2.43 & -1.60 & 2.30 \\
\hline Fp2 & 168.30 & 23.46 & -3.06 & 2.23 & -1.73 & 2.19 & 180.34 & 23.79 & -3.15 & 2.22 & -1.58 & 2.19 \\
\hline F7 & 170.40 & 25.64 & -1.71 & 3.65 & -1.57 & 2.70 & 181.30 & 25.63 & -2.86 & 2.93 & -1.84 & 2.65 \\
\hline F8 & 171.69 & 21.18 & -3.29 & 2.39 & -1.96 & 2.14 & 177.97 & 26.01 & -3.30 & 2.03 & -1.91 & 2.05 \\
\hline F3 & 172.28 & 24.33 & -5.45 & 2.97 & -3.43 & 2.27 & 179.81 & 22.64 & -5.05 & 2.75 & -2.94 & 2.05 \\
\hline F4 & 169.88 & 22.36 & -5.39 & 2.25 & -3.34 & 1.77 & 178.12 & 22.84 & -5.33 & 2.58 & -3.13 & 2.02 \\
\hline $\mathrm{Fz}$ & 175.50 & 27.26 & -5.72 & 2.75 & -3.64 & 2.14 & 178.72 & 22.98 & -5.17 & 2.33 & -2.85 & 1.91 \\
\hline C3 & 167.34 & 28.30 & -5.00 & 3.49 & -3.20 & 2.49 & 176.98 & 25.40 & -4.26 & 3.09 & -2.45 & 2.24 \\
\hline $\mathrm{C} 4$ & 166.92 & 23.41 & -4.69 & 3.06 & -2.86 & 2.35 & 177.44 & 24.18 & -4.18 & 2.70 & -2.48 & 1.82 \\
\hline $\mathrm{Cz}$ & 170.25 & 22.35 & -5.17 & 3.23 & -2.98 & 2.46 & 178.92 & 25.55 & -4.14 & 2.58 & -2.08 & 2.00 \\
\hline
\end{tabular}




\section{DISCUSSION}

The comparison between a group of subjects with a multigenerational family history of alcoholism and a control group indicated that there were no differences between the groups for MMN peak latency, peak amplitude, and mean amplitude. These results were in agreement with those previously found in a sample of young HR subjects ${ }^{45}$ and did not coincide with those reporting arger MMN amplitude in adult children pf alcoholics ${ }^{46}$.

These results indicated that preattentive mechanisms of mismatch detection that have been found to be sensitive to the acute and chronic effects of alcohol ${ }^{40,44}$ were not impaired in nonaffected genetically vulnerable subjects. Previous reports have found that HR subjects manifest anomalies in ERP components related to controlled attention and discrimination processes, such as P300 1,15 the Late Positive Complex ${ }^{52,53}$, or $\mathrm{N} 400{ }^{54}$, and even in those related to the switch of attention focus on intrusive events in the attended channel ${ }^{3-6,38}$., However, there was no evidence of abnormal values in several electrophysiological indexes of automatic processing of sensory input, either in specifically designed studies (auditory brainstem potentials) ${ }^{55}$ or evaluated in the course of the P3 studies referred to previously (N1, P2). The present report evaluating MMN supports the conclusion that the differences between children of alcoholics and controls do not appear in the automatic processing of auditory information.

Because abnormal MMN amplitude in HR subjects has been found in one laboratory ${ }^{46}$ the origin of the different results should be briefly discussed. The studies differed in the age range of the samples (adults versus children), but this does not seem to be the key to the discrepant results: MMN appears early in ontogenetic development and presents similar values from 6 or 7 years of age to adulthood 56,57 . Furthermore, preliminary analyses of the interactions between risk group and age in the MMN parameters at the present study discarded a progressive appearance of differences during development in the age range assessed. A more important difference between the present sample and that assessed by Zhang and colleagues could be the psychopathological background of alcoholic families. In the present investigation, not only an individual but also a family history of psychiatric disorders were exclusionary criteria. Moreover, the presence of psychopathological traits other than alcoholism was small in all of the sample interviewed (50 alcoholic families). Abnormal ERP values have been associated not only with familial vulnerability to alcoholism, but also with the concurrence of other psychopathological disorders ${ }^{30}{ }^{31}$. The absence of this psychopathological background could be the reason for the absence of abnormalities in MMN in subjects with a family history of alcoholism found in this research.

In summary, the present study indicated that electrical brain activity associated with preattentive detection of a deviant stimulus reflected in MMN is not altered in a sample of young children of alcoholics with a high family density of alcoholism and an absence of other psychopathological traits. 


\section{ACKNOWLEDGMENTS}

We thank the staff of UTA at the Hospital Xeral de Santiago de Compostela, Asociación de Ex-Alcohólicos de A Coruña, and Asociación Viguesa de Alcohología for their help in recruiting the sample.

\section{FUNDING}

This research was supported by the Spanish Ministry of Education and Culture (DGICYT) Grant PB95-0856.

\section{REFERENCES}

1. Begleiter H, Porjesz B, Bihari B, Kissin B: Event-related brain potentials in boys at risk for alcoholism. Science 225:1493-1496, 1984

2. Begleiter $\mathrm{H}$, Porjesz B, Rawlings R, Eckardt M: Auditory recovery function and P3 in boys at risk for alcoholism. Alcohol 4:315-321, 1987

3. Whipple SC, Berman SM, Noble EP: Event-related potentials in alcoholic fathers and their sons. Alcohol 8:321-327, 1991

4. Hill SY, Steinhauer SR: Assessment of prepubertal and postpubertal boys and girls at risk for developing alcoholism with P300 from a visual discrimination task. J Stud Alcohol 54:350-358, 1993

5. Steinhauer SR, Hill SY: Auditory event-related potentials in children at high risk for alcoholism. J Stud Alcohol 54:408-421, 1993

6. Sharma A, Malhotra S, Raghunathan M, Malhotra A: A study of event-related potential. P3 characteristics in children of alcoholics. Addict Biol 2:431-438, 1997

7. O'Connor S, Hesselbrock VM, Tasman A: Correlates of increased risk for alcoholism in young men. Prog Neuropsychopharmacol Biol Psychiatry 10:211-218, 1986

8. O'Connor S, Hesselbrock VM, Tasman A, DePalma N: P3 amplitudes in two distinct tasks are decreased in young men with a history of paternal alcoholism. Alcohol 4:323-330, 1987

9. Porjesz B, Begleiter $\mathrm{H}$ : Event-related potentials in individuals at risk for alcoholism. Alcohol 7:465-469, 1990

10. Hesselbrock VM, Bauer LO, O'Connor S, Gillen R: Reduced P300 amplitude in relation to family history of alcoholism and antisocial personality disorder among young men at risk for alcoholism. Alcohol Alcohol 2(Suppl.):95-100, 1993

11. O'Connor S, Bauer LO, Tasman A, Hesselbrock VM: Reduced P3 amplitudes are associated with both a family history of alcoholism and antisocial personality disorder. Prog Neuropsychopharmacol Biol Psychiatry 18:1307-1321, 1994

12. Benegal V, Jania S, Subbukrishna DK, Channabasavana SM: P300 amplitudes vary inversely with continuum of risk in first degree male relatives of alcoholics. Psychiat Genet 5:149-156, 1995 
13. Ramachandran G, Porjesz B, Begleiter $\mathrm{H}$, Litke A: A simple auditory oddball task in young adult males at high risk for alcoholism. Alcohol Clin Exp Res 20:9-15, 1996

14. Cohen HL, Porjesz B, Begleiter H, Wang A: Neuroelectric correlates of response production and inhibition in individuals at risk to develop alcoholism. Biol Psychiatry 42:57-67, 1997

15. Ramsey SE, Finn PR: P300 from men with a family history of alcoholism under different incentive conditions. J Stud Alcohol 58:606- 616, 1997

16. Pfefferbaum A, Ford JM, White PM, Mathalon D: Event-related potentials in alcoholic men: P3 amplitude reflects family history but not alcoholic consumption. Alcohol Clin Exp Res 15:839-850, 1991

17. Cohen HL, Wang W, Porjesz B, Begleiter H: Auditory P300 in young alcoholics: Regional response characteristics. Alcohol Clin Exp Res 19:469-475, 1995

18. Porjesz B, Begleiter $\mathrm{H}$ : Genetic bases of the event-related potentials and their relationship to alcoholism and alcohol use. J Clin Neurophysiol (in press)

19. Polich J, Bloom FE: P300 and alcohol consumption in normals and individuals at risk for alcoholism. A preliminary report. Prog Neuropsychopharmacol Biol Psychiatry 10:201-210, 1986

20. Polich J, Bloom FE: P300 from normal and adult children of alcoholics. Alcohol 4:301-305, 1987

21. Baribeau J, Ethier M, Braun CMJ: Neurophysiological assessment of selective attention in males at risk for alcoholism, in Johnson R, Rohrbaugh JW, Parasuraman R (eds): Current Trends in Event-Related Potential Research. Amsterdam, Elsevier Science Publishers, 1987, pp 651-656

22. Steinhauer SR, Hill SY, Zubin J: Event-related potentials in alcoholics and their first-degree relatives. Alcohol 4:307-31, 1987

23. Polich J, Burns T, Bloom FE: P300 and the risk for alcoholism: Family history, task difficulty, and gender. Alcohol Clin Exp Res 12:248- 254, 1988

24. Polich J, Haier RJ, Buchsbaum M, Bloom FE: Assessment of young men at risk for alcoholism with P300 from a visual discrimination task. J Stud Alcohol 49:186-190, 1988

25. Hill SY, Steinhauer SR, Park J, Zubin J: Event-related potential characteristics in children of alcoholics from high density families. Alcohol Clin Exp Res 14:6-16, 1990

26. Bauer LO, Hesselbrock VM, O'Connor S, Roberts L: P300 differences between non-alcoholic young men at average and above-average risk for alcoholism: Effects of distraction and task modality. Prog Neuropsychopharmacol Biol Psychiatry 18:263-277, 1994

27. Hill SY, Steinhauer SR, Locke J: Event-related potentials in alcoholic men, their high-risk male relatives and low-risk male controls. Alcohol Clin Exp Res 19:567-576, 1995 
28. Rodríguez Holguín S, Corral M, Cadaveira F: Visual and auditory event-related potentials in young children of alcoholics from high and low density families. Alcohol Clin Exp Res 22:87-96, 1998

29. Hesselbrock VM, Bauer LO, O'Connor S, Gillen R: Reduced P300 amplitude in relation to family history of alcoholism and antisocial personality disorder among young men at risk for alcoholism. Alcohol Alcohol 2(Suppl.):95-100, 1993

30 Bauer LO, Hesselbrock VM, O'Connor S, Roberts L: P300 differences between non-alcoholic young men at average and above-average risk for alcoholism: Effects of distraction task and modality. Progr Neuropsychopharmacol Biol Psychiatry 18:263-277, 1994

31. Bauer LO, O'Connor S, Hesselbrock VM: Frontal P300 decrements in antisocial personality disorder. Alcohol Clin Exp Res 18:1300-1305, 1994

32. Polich J, Pollock VE, Bloom FE: Meta-analysis of P300 amplitude from males at risk for alcoholism. Psycho! Bull 115:55-73, 1994

33. Begleiter $\mathrm{H}$, Porjesz $\mathrm{B}$ : Neurophysiological phenotypic factors in the development of alcoholism, in Begleiter H, Kissin B (eds): Alcohol and Alcoholism, vol 1, Genetics of Alcoholism. New York, Oxford University Press, 1995, pp 269-293

34. Comerchero MD, Katayama J, Polich J: P3a and P3b from auditory and visual stimuli. Psychophysiology 34:S27, 1997

35. Katayama J, Polich J: Stimulus context determines P3a and P3b. Psychophysiology 35:23-33, 1998

36. Van der Stelt O, Gunning WB, Snel J, Kok A: Children of alcoholics: Brain potentials associated with novelty. Alcohol Clin Exp Res 20:34A, 1996

37. Rodríguez Holguín S, Corral M, Cadaveira F: Event-related potentials elicited by infrequent non-target stimuli in young children of alcoholics: Family history and gender differences. Alcohol Alcohol 33:281-290, 1998

38. Deleted in proof

39. Näätänen R: The role of attention in auditory information processing as revealed by event-related potentials and other brain measures of cognitive function. Behav Brain Sci 13:201-232, 1990

40. Jääskeläinen IP, Pekkonen E, Alho K, Sinclair JD, Sillanaukee P, Näätänen R: Dose-related effect of alcohol on mismatch negativity and reaction time performance. Alcohol 12:491-495, 1995

41. Jääskeläinen IP, Lehtokoski A, Alho K, Kujala T, Pekkonen E, Sinclair JD, Näätänen R, Sillanaukee P: Low dose of ethanol suppresses mismatch negativity of auditory event-related potentials. Alcohol Clin Exp Res 19:607-610, 1995

42. Jääskeläinen IP, Pekkonen $E$, Hirvonen $J$, Sillandukee $P$, Näätänen R: Mismatch negativity subcomponents and ethyl alcohol. Biol Psycho! 43:13-25, 1996

43. Realmuto G, Begleiter H, Odencrantz J, Porjesz B: Event-related potential evidence of dysfunction in automatic processing in abstinent alcoholics. Biol Psychiatry 33:594-601, 1993 
44. Kathmann N, Wagner M, Rendtorff N, Engel RR: Delayed peak latency of the mismatch negativity in schizophrenics and alcoholics. Biol Psychiatry 37:754-757, 1995

45. Van der Stell O, Gunning WB, Snel J, Kok A: No electrocortical evidence of automatic mismatch dysfunction in children of alcoholics. Alcohol Clin Exp Res 21:569575,1997

46. Zhang $\mathrm{XL}$, Begleiter $\mathrm{H}$, Porjesz $\mathrm{B}$ : Mismatch negativity in high risk subjects for alcoholism. Alcohol Clin Exp Res (in press), 1998

47. American Psychiatric Association: Diagnostic and Statistical Manual of Mental Disorders, ed 3-rev (DSM-III-R). Washington, D.C., American Psychiatric Association, 1987

48. Bucholz KK, Cadoret R, Cloninger CR, Dinwiddie SH, Hesselbrock VM, Nurnberger JI, Reich T, Schmidt I, Schuckit MA: A new semi-structured psychiatric interview for use in genetic linkage studies: A report of the reliability of the SSAGA. J Stud Alcohol 55:149-158, 1994

49. Polich J, Kok A: Cognitive and biological determinants of P300: An integrative review. Biol Psychol 41:103-146, 1995

50. American Electroencephalographic Society: American Electroencephalographic Society guidelines for standard electrode position nomenclature. J Clin Neurophysiol 8:200-202, 1991

51. Semlitsch HV, Anderer P, Schuster P, Presslich O: A solution for reliable and valid reduction of ocular artifacts applied to the P300 ERP. Psychophysiology 23:695703, 1986

52. Whipple SC, Parker ES, Noble EP: An atypical neurocognitive profile in alcoholic fathers and their sons. J Stud Alcohol 49:240-244, 1988

53. Berman SM, Martinez RA, Noble EP: Familial alcoholism and ERPs: Differences in probability sensitivity? Alcohol Alcohol 28:695-707, 1993

54. Schmidt AL, Neville HJ: Language processing in men at risk for alcoholism: An event-related potential study. Alcohol 2:529-533, 1985

55. Begleiter $\mathrm{H}$, Porjesz B, Bihari B: Auditory brainstem potentials in sons of alcoholic fathers. Alcohol Clin Exp Res 11:477-480, 1987

56. Csepe V: On the origin and development of the mismatch negativity. Ear Hear 16:91-104, 1995

57. Kurtzberg D, Vaughan HG, Kreuzer JA, Fliegler KZ: Developmental studies and clinical application of mismatch negativity: Problems and prospects. Ear Hear 16:105117,1995 